\title{
Erratum to: Efficacy of $N$-acetylcysteine on neuroclinical, biochemical, and histopathological parameters in experimental spinal cord trauma: comparison with methylprednisolone
}

\author{
U. Y. Çavuş • A. Yılmaz • M. N. Aytekin • \\ G. Öztürk · A. Albayrak · S. Yıldırım • \\ I. Ăğ|r
}

Published online: 29 January 2014

(c) Springer-Verlag Berlin Heidelberg 2014

\section{Erratum to: Trauma Emerg Surg \\ DOI 10.1007/s00068-013-0349-4}

In the published original article, the name of the fourth author is not given correct:

The correct name is: Gülfer Öztürk

The online version of the original article can be found under doi:10.1007/s00068-013-0349-4.

\section{U. Y. Çavuş $(\bowtie)$}

Department of Emergency Medicine, Dışkapı Yıldırım Beyazıt Training and Research Hospital, Ankara, Turkey

e-mail: acildrumut@yahoo.com

\section{A. Yilmaz}

Department of Emergency Medicine, Bitlis State Hospital, Bitlis, Turkey

M. N. Aytekin

Department of Orthopedics and Traumatology, Atatürk Training and Research Hospital, Ankara, Turkey

G. Öztürk

Department of Biochemistry, Dışkapı Yıldırım Beyazıt Training and Research Hospital, Ankara, Turkey
A. Albayrak
Department of Pathology, Dışkapı Yıldırım Beyazıt Training and Research Hospital, Ankara, Turkey
S. Yildirım
Department of Emergency Medicine, Ağrı State Hospital, Ağri, Turkey
İ. Ağır
Department of Orthopedics and Traumatology, Adiyaman
University Training and Research Hospital, Adıyaman, Turkey 